\title{
EN TORNO A LAS NUEVAS CABEZAS OLMECAS
}

\section{Por Beatriz de la Fuente}

Durante las temporadas de exploraciones arqueológicas de 1969 y de 1970, fueron descubiertas en el sitio olmeca de San Lorenzo Tenochtitlan, Veracruz, dos imponentes cabezas que vienen a integrarse con las otras siete encontradas en ese mismo lugar. A la cabeza número 8 se le dio el nombre de monumento 53, y a la número 9 el de monumento 61. ${ }^{1}$ Existen además en la región olmeca otras siete cabezas colosales; cuatro proceden de La Venta, Tabasco; una de Tres Zapotes; otra de Nestepe, Veracrur, y una más se encuentra en Santiago Tuxtla, también Veracruz. Entre la escultura olmeca monumental, estas cabezas constituyen el más impresionante conjunto de obras de arte.

Las dos recién descubiertas están talladas en piedra andesítica, como todos los 65 monumentos esculpidos que se han encontrado en San Lorenzo. La cabeza número 8 está sumamente erosionada y muestra marcas visibles de intentos destructivos; la número 9 es, en cambio, la que se halla en mejor estado de conservación, sin huella alguna de la conocida destrucción ritual. Mientras que la 8 se encontró a poca distancia de la superficie, la 9 "fue enterrada en un pozo amplísimo... con una profundidad actual de 4 metros". 2 Esta última, junto con la SL7 -ahora sólo una informe masa pétrea- es de las que consta que fueron deliberadamente enterradas; las siete restantes se han descubierto en las barrancas que limitan la meseta artificial de San Lorenzo, a donde han ido a parar por el natural proceso de erosión, ya que fueron clepositadas en un relleno superficial.

M.D. Coe observó, durante sus exploraciones, ${ }^{3}$ que los monumentos de San Lorenzo habian sido mutilados intencionalmente, y que su entierro en anchos pozos o en la capa de relleno obedecía a una disposición deliberada, pues se colocaron en hileras orientadas NorteSur Oriente-Poniente. Esto debió de haber ocurrido hacia el fin de la fase San Lorenzo, fechada entre 1200 y 900 a.J.C. El citado arqueólogo concluye interpretando "la colocación final de las piedras

1 Mantengo la designación propuesta por Clewlow et al.; 1967: 7 y 16 en que se usan las iniciales del lugar y el número de acuerdo con el orden de su descubriuniento. El mon. 33 es SL.8 y el mon. 6l es SI.9. SL8 fue descubierto por los arqueólogos F, Beverido y R. Callegos y SL9 por J. Briggemann.

2 Briggemann 1970: 18 .

3 Coe, 1966, 1967, 1968. 
como un acto revolucionario posiblemente de los habitantes de la misma zona de San Lorenzo Tenochtitlan y no el resultado de una invasión exterior". *

El fenómeno de mutilación intencional ha sido notado por casi todos los arqueólogos que han hecho exploraciones en la zona olmeca; aparece en todos los tipos y variaciones de monumentos de piedra, y en grados que oscilan desde la destrucción casi completa hasta la realización de un pequeño orificio o hendidura. Existen diferentes tipos de mutilación intencional, en forma de muescas, de acanaladuras afiladas, de nichos rectangulares, de estrias y de hoyos. De las cabezas colosales, solamente la de Nestepe y la de San Lorenzo número 9 no muestran signos aparentes de destrucción intencional (por lo demás, en ninguna de ellas se ha podido efectuar una inspección adecuada). Lo sorprendente es que en las cabezas de San Lorenzo los intentos destructivos son tan reducidos que en nada afectan la espectacular apariencia visual de las mismas. Poilría suponerse que los escasos hoyos y muescas que presentan, simbolizan la intención mutilatoria, o bien que, como los monumentos fueron derrumbados, ese derrocamiento es una alternativa de la misma actitud demoledora.

Por otra parte el enterramiento de objetos valiosos, que se tenían en grande estima, fue fenómeno cultural frecuente entre los antiguos mesoamericanos. Ricas ofrendas acompañaban bajo tierra a monumentos conmemorativos, indicaban la consagración de edificios religiosos, y las más preciadas joyas eran enterradas con los difuntos. A un concepto semejante, que tiene además del sentido religioso otro de carácter cósmico, obedece la costumbre de cubrir lo que ya se edificó, de enterrar el pasado, a veces al final de los ciclos recurrentes cada 52 años, como lo muestran los cientos de construcciones que a manera de cajas huecas van encerrando en su interior edificios de épocas anteriores.

También la mutilación intencional de las imágenes fue práctica común entre otros pobladores de la América Media. Cuántas estelas mayas han sobrevivido a los siglos en magnífico estado, pero con los rostros de las figuras que glorifican -y precisamente los rostros- destruidos en época no muy lejana de aquella en que fueron esculpidas. Así perecía la imagen visible, la que, acaso por el despotismo que representaba, era rechazada.

Estas dos actitudes culturales parecen ser la expresión de sentimientos contradictorios. Se busca la destrucción, pero no el aniquilamiento to-

4Coe, 1967: 10. 
tal; se mutila, pero no se mata. Es una particular expresión iconoclasta en que se rechazan las imágenes, tal vez por su presencia corpórea y material; pero en que se respeta otra realidad absoluta, perceptible sólo como iclea impersonificable.

La cabeza número 8 de Sin Lorenzo tiene estructura oval, y vista de frente es un tanto alargada. Guarda bastante parecido con la número 2 del mismo sitio; pero, como todas las demás, tiene ligeras variaciones en la fisonomía y en el tocado a manera de casco que le cubre la cabera. Recién descubierta recordaba la fiereza del gesto felino; hoy en día, ya limpia, refleja la misma expresión serena $y$ confiada que distingue y ennollece a las cabezas de la que podríamos llamar escuela de San Lorenzo. Los ojos elípticos con la pupila realzada miran fijos e imperturbables, y la boca entreabierta muestra los dientes con gran naturalidacl. El casco va ceñido hasta las cejas, pero la banda circular en que termina se corta al frente y deja ver el diseño del casco mismo, que consiste en dos pares de cartuchos o anillos incisos colocados simétricamente $y$ que son iguales a las orejeras de SL2.

Por su parte, la cabeza número 9, de forma algo más achatada, se asemeja notablemente en el perfil a SL5, y a SLl en su extraordinaria calidacl artística. Desafortunadamente, no es aún posible admirarla en toda su majestad, ya que no ha sido movida del pozo en que fue localizada. Se pueden, sin embargo, advertir sus particularidades: unos como mechones de pelo que salen del casco hacia la parte de atrás de la cabeza, y un símbolo a manera de lazo doblado que "podría representar las cejas del jaguar" "se repite a lo largo de la faja inferior del casco; dos lengüetas trapetoidales cuelgan de éste delante de las estilizadas orejas, y una amplia vírgula plana es el pendiente que cac bajo ellas. Los rasgos, del más puro aspecto olmeca, fueron ejecutados con perfección indecible; el entrecejo carnoso, resultante de la presión del casco, los ojos ovales perfilados en realce, las amplias aletas de la nariz. las mejillas modeladas y los sensuales labios integran de manera excepcional el animado rostro de piedra.

Al observar estas nuevas cabezas olmecas, volvió a inquietarme la sensación de no comprender, y el deseo, tal vez irrealizable, de aproximarme al mensaje humano y universal que de ellas emana. Los escritos sobre el tema son ya considerables y no pretendo abundar en ellos. Se orientan sobre todo al análisis formal, a posibles secuencias tempo-

5 Bruggemann, 1970: 18. 
rales y a supuestas interpretaciones de lo que las cabezas representan. Un muy completo estudio elaborado por estudiantes de la Universidad de California ${ }^{\text {" }}$ sintetiza los trabajos anteriores, describe y agrupa las cabezas entonces conocidas - doce- de acuerdo con sus medidas, símbolos, ornamentos, y formas de los rasgos faciales, en tres conjuntos que corresponden a lo que considero como talleres o escuelas regionales de San Lorenzo, de La Venta y de Tres Zapotes. Las dos cabezas en que hoy me ocupo se incorporan plenamente, por su estilo artistico y por los símbolos que tienen, al resto de la escuela de San Lorenzo. Todas las cabezas son más o menos contemporáneas, o sea que fueron talladas en un lapso de cien a doscientos años.

Pero sin duda lo que más ha interesado a arqueólogos y a historia. dores es la identificación de las caberas; es decir, qué o a quiénes representan. G. Kubler ${ }^{7}$ opina que son retratos ideales; Medellín Zenil ${ }^{8}$ y Coe, ${ }^{9}$ que se trata de individuos negros o de aspecto negroide; o son guerreros, según Coe, ${ }^{10}$ Piña Chan y Covarrubias, ${ }^{11}$ quienes también sugieren que representan jugadores de pelota y que son testimonio de sacrificios por decapitación. ${ }^{12}$ Para Stirling ${ }^{13}$ y para Armillas ${ }^{14}$ son retratos de jefes; según Bernal, ${ }^{1 "}$ retratos genéricos de jefes o de guerreros; para Wicker ${ }^{16}$ monumentos conmemorativos a jefes muertos, $y$ para Westheim ${ }^{17}$ son dioses de la vegetación. Otros aventuran hipótesis sugestivas, como Covarrubias, ${ }^{18}$ quien notó que las cabezas de La Venta se orientaban al norte, lo que podría implicar que "fueran marcas astronómicas", y como Kubler, ${ }^{10}$ al decir que "las cabezas colosales manifiestan un deseo faraónico de eternidad, de sobrevivencia física más allá de los accidentes del tiempo". En un trabajo reciente, Coe los considera retratos de reyes de la dinastía de los jaguares, ${ }^{20}$

- Clewlow et al., 1967.

7 Kubler, 1961; 67.

8 Medellín Zenil, 1963.

2 Coe, 1965: 741.

10 Coe, 1965: 763.764.

11 Piña Chan y Covarrubias, 1964: 36.

12 Piña Chan y Covarrubias, 1964: $303-304$.

13 Stirling 1955, 1965: 733.

14 Armillas 1964.

16 Bernal 1968: 75.

16 Citado por Bernal 1968: 75.

17 Westheim 1965: 131.

18 Covarrubias 1946: 97.

19 Kubler, 1962: 69.

20 Coe, 1970. 
DOI: http://dx.doi.org/10.22201/iie.18703062e.1971.40.937

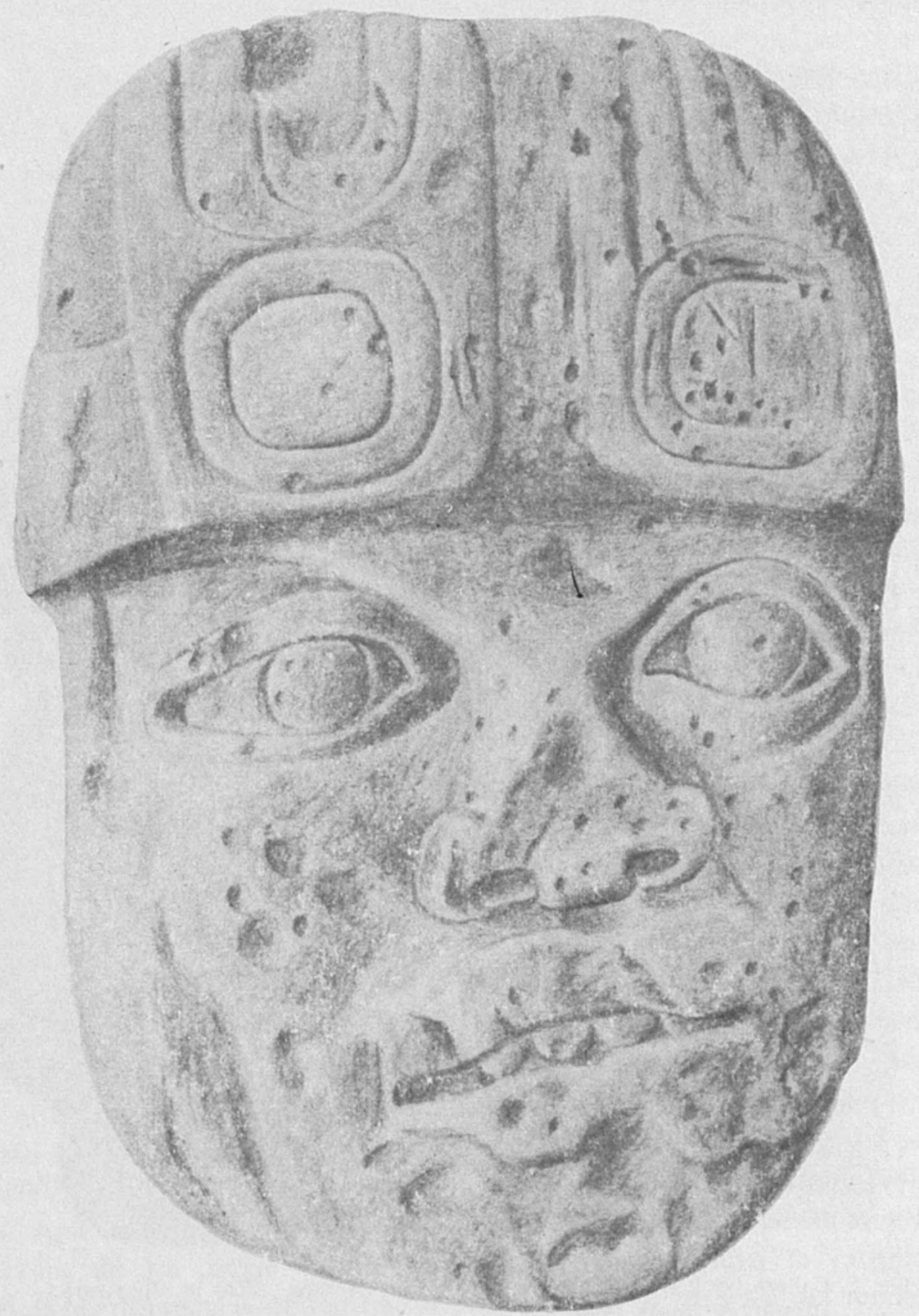

Fig. I. Cabeza No 8 de San Lorenzo, Veracruz, México. $(2.25 \mathrm{~m}$. de altura.) Dibujo de Andy Seuffert. 
DOI: http://dx.doi.org/10.22201/iie.18703062e.1971.40.937

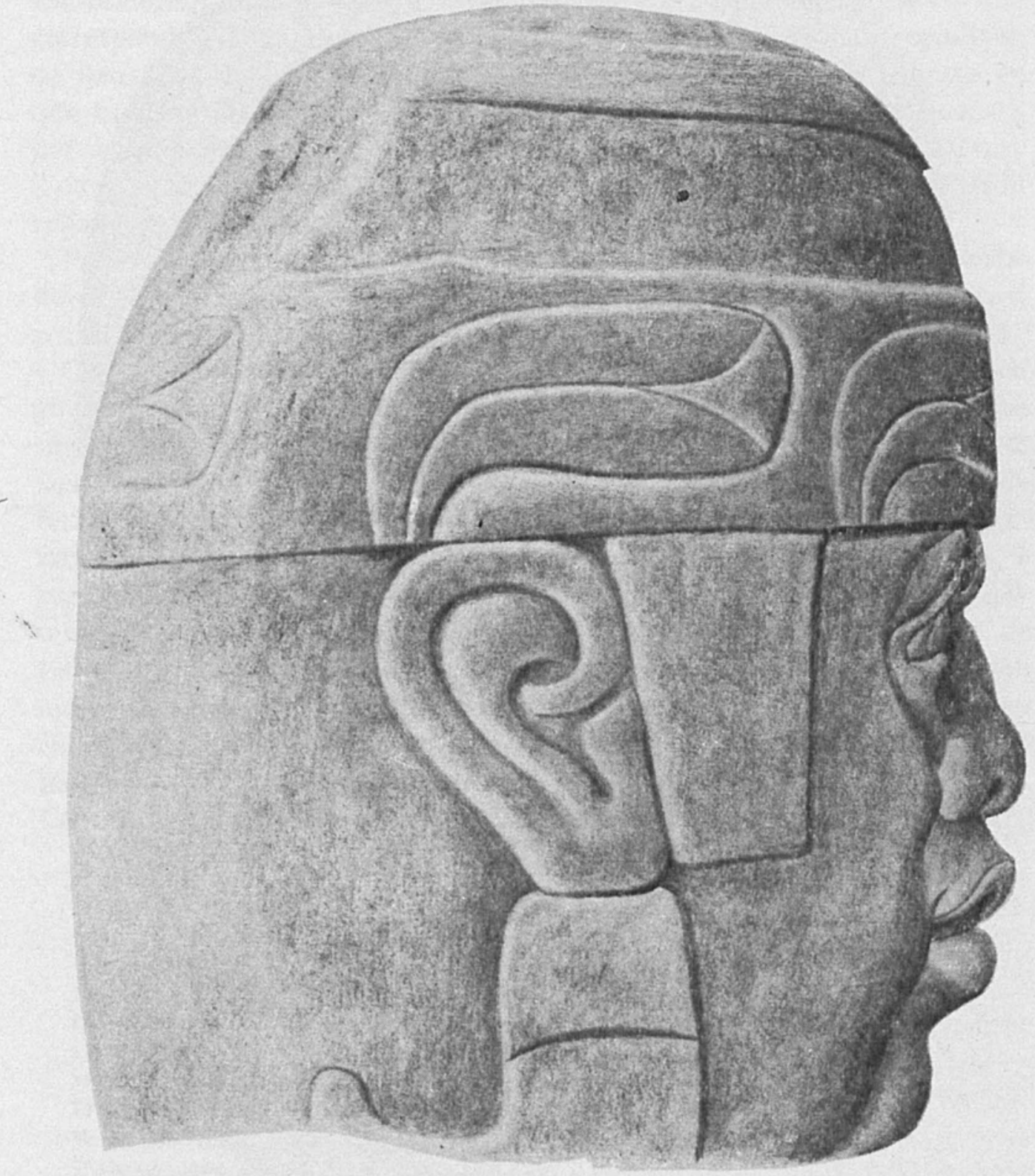

Fig. 2. Cabeza No 9 de San Lorenzo, Veracruz, México. $(2.20 \mathrm{~m}$. de altura.) Dibujo de Andy Seuffert. 
y es el único que intenta una explicación de carácter sociológicoreligioso. Es evidente que un fenómeno artístico tan importante como la talla realista cle caberas gigantescas, obedece a profundas motivaciones culturales.

Aun cuando la práctica de representar cabezas separadas del cuerpo es infrecuente, no es clel todo excepcional. Aunque no muy difundida, la costumbre cultural de la prehistoria en que la cabeza del difunto, $\sin$ cuerpo, se pintaba de rojo ocre para preservar la vitalidad de la sangre, puede haber precedido una larga trayectoria que a la postre se convirtió en fenómeno artístico. En el arte occidental, la cabe ta, como asiento de la inteligencia y de los órganos más evolucionados del hombre, ha simbolizado al hombre mismo y su naturalera divina.

En Mesnamérica existen, además de las caberas colosales olmecas, otras tradiciones escultóricas que expresan conceptos similares en maneras distintas. Ellas son, entre otras, las cabezas de la escuela de Monte Alto, Cuatemala; las "cabecitas colosales" de la Mixteca Baja; las cabezas "fantásticas" de Cerro de las Mesas, Estero Rabón y Medias Aguas, Veracrur: la del hombre viejo de El Baúl, Guatemala, y la de la Coyolxauhqui atteca. Es así como los olmecas iniciaron una secuencia que culminaria en el mundo náhuatl; por lo tanto, no es circunstancial la presencia de cabezas en distintas regiones y it todo lo largo de la historia de la civilización mesoamericana.

Como toda expresión de arte figurativo, las cabezas olmecas tienen un aspecto formal externo, constituido por su estructura geométrica y por los elementos iconográficos reconocibles de acuerdo con nuestra experiencia visible. Las caberas son imagenes, efigies de seres humanos que muestran una serie de convenciones artisticas, de rasgos comunes, y $\sin$ ducla se refleja en ellas un arquetípico ideal de belleza. Todas tienen la misma composición armónica en sus proporciones, ejes y distancias, pertenecen al mismo tipo racial, llevan aplanada la parte de atrás y usan algo como un casco que les cubre la cabera.

Sin embargo, en cada una cle ellas es distinto el cuidado y la propiedad de la expresión; son diferentes lon símbolos del tocado que tienen una función similar a la del estandarte o pendón de la persona, y los adornos de las orejas varían. Las convenciones indican la categoría social; las diferencias de expresión que apumtan al carácter del modelo, señalan la individualidad del retrato. 
Participo de la opinión del doctor Coe 21 de que son retratos de "reyes", aun cuanclo me parece más adecuado pensar en jefes supremos que reunían en sí los poderes religiosos, políticos y sociales. Son retratos oficiales de la dinastía que controlaba al pueblo y a la cual se le debía, como a la que rigió a los antiguos egipcios, un culto de carácter religioso. Son varios los estudios ${ }^{22}$ que señalan la importancia que tuvo dentro del mundo mesoamericano la representación dinástica, la ascendencia ilustre que justificaba la aristocracia heredacla. Licito es suponer que los olmecas retrataron por las mismas razones a sus jefes supremos. Quizí sean los retratos de una sola dinastía en cada lugar - un lapso de cien a doscientos años es breve-, e inclusive es posible que alguno de los gobernantes fuese retratado en dos oca. siones, de donde el parecido mayor que entre sí guardan algunas cabezas.

Ahora bien, la presencia más o menos generalizada de cabezas en Mesoamérica, me induce a pensar en ellas como símbolos culturales con un significado intrínseco, con un contenido por comunicar, más profundo y universal que el que se clesprende de la mera apariencia exterior. Es la cabe a el recipiente que aloja las capacidades superiores del hombre, los poderes creadores, el centro de la vida espiritual. En ella reside lo que se considera inmutable y eterno: la capacidad de comulgar con lo sobrenatural. Su forma misma: la esfera, es símbolo del cosmos, la totalidad de lo conocido. La cabeza es el asiento de la naturaleza divina del hombre, por ello no fueron aniquiladas las majestuosas cabezas oimecas.

En resolución, es dable suponer que a las cabezas, lo mismo que a sus modelos de noble estirpe, se les atribuían poderes sobrenaturales, y que acaso fueron objetos de culto y homenaje debido a las fuerzas mágicas que en ellas se consideraban asentadas.

He anotado líneas arriba que resulta desproporcionada, particularmente en las caberas de San Lorenıo, la intención destructiva con respecto al daño en ellas producido. No me cabe duda de que si los olmecas hubieran decidido aniquilarlas, lo habrian logrado. Algo intangible los detuvo siempre; el temor, tal vez, de ir en contra del poder mágico religioso simbolizado por ellas.

Así pues, la apariencia temporal, las personas particulares suscitaron

21 Coe 1967: 74 y 1970.

22 Proskouriakoff 1960, 1963. 1964. 
la violencia y el deseo de destruirlas; su naturaleza mágica las salvaguardó eternamente. Los ataques y los intentos de mutilación fueron contra personas individuales, contra esos "reyes" tiranos y autoritarios, pero no en contra del principio: se mantuvo el respeto y el temor a la divinidad real. La revolución, que tuvo por meta derrocar las poderosas dinastías olmecas fue de orden político y se hizo para destruir a determinados dignatarios; no fue una revolución de caracter ideológico, pues el mismo orden teocrático gobernó a Mesoamérica por siglos. En un momento se pretendió aniquilar al hombre histórico y temporal; pero como su imagen no podía desligarse de su aspecto de eternidad religiosa, se la enterró ritualmente, para conservar esa fuerza mágica, inclestructible, que de ella emanaba.

Por lo que se refiere ya a lo caracteristicamente plástico, puede asegurarse que procos monumentos en el arte de la América Antigua son comparables en grandera escultórica a las cabezas colosales olmecas. Quienes las ejecutaron tuvieron profundos conocimientos en la realización espacial de la masa, que apela a las reacciones visuales y táctiles y a la sensación de peso. Las cabezas reúnen tres factores plásticos esenciales: la cualidad táctil cle las superficies, la sensación de volumen, y la realización sintética y de pesantez de la masa. A pesar de que las formas están sujetas a la configuración general de la masa y de que nunca se proyectan audarmente en el espacio, su ejecución es de un perfecto modelado. Las diferentes partes de la cara -ojos, mejillas, narices y boca- expresan en sus majestuosas proporciones un conocimiento sabio y un sutil manejo de las suaves depresiones y las proyecciones adecuadlas, siempre con perfiles redondeados. Es sobre todo la realización sintética lo que produce el impacto de forma sólida y de monumentalidad; el logro de la integración del volumen y la masa es resultado de la concentración en formas directas y simples. Las cabezas olmecas son perfectas en su pure $z$ a artistica; nada es accesorio en la forma, y en el concepto todo es esencial.

He pretendido, partiendo de datos objetivos proporcionados por la historia, la arqueología, la antropología y otras ciencias, llegar a la comprensión del significado profundo de las obras sustanciales de la escultura olmeca. Sć que el misterio subsiste intacto. Alli estín, guardándolo. esas que son para nosotros obras de arte excepcionales, y que en su momento fueron realizadas por causas no puramente artisticas. 


\section{BIBLIOGRAFIA}

BERNAL, IGNACIO.

1968 El mundo olmeca, Editorial Porrúa, México.

Brüggemans, Jurgen Y Marik, Areil Hers.

1970 "Exploraciones arqueológicas en San Lorenzo Tenochtitlan." Boletin $I N^{+} A H$, Nọ 39; 18-23, México.

Cilewlow, Williay C., Richard A. Cowan, James F. O'Cornell y Carlos BENEMANN.

1967 "Colossal Heads of the Oimec Culture." Contributions of the Unirersity of Californa. Arhaeological Research Facility. No 4, Berkelcy, California.

Coe, Michael D.

1965 "The Olmec Style and its Distribution." Handbook of Middle American Indians, Volume three, Part two, pp. 739-775. Robert Wauchope. General Editor, I'niversity of Texas Press, Austin.

1966 "Exploraciones Arqueológicas en San Lorenzo Tenochtitlan, Veracrur." Boletin INAH, Nọ 24, pp. 21-25, México, S.E.P. (junio) .

1967 "La segunda temporada en San Lorenzo Tenochtitlan, Veracruz." Boletin INAH, No 28, junio. México, SEP, pp. 1-10.

1968 "San Lorenzo and the Olmec Civiliration." Dumbarton Oaks. Conference on the Olmer, Trustees for Harvard University, pp. 41-71.

Elizabeth P. Benson Editor, Dumbarton Oaks Research Library and Collection. Washington, D. C.

1970 Olmec Jaguars and Olmer Kings. Conferencia presentada en Dumbarton Oaks, Washington el 2 de nov. de 1970 (copia mimeográfica).

Covarrubias, Miguel.

1946 México South, the Isthmus of Tehuantepec. A. Knopf, New York.

Kubler, George.

1961 Three Regions of Primitice Art. Museum of Primitive Art, Lecture Series No 2, New York.

1962 The Art and Arrhitecture of Ancient America. Penguin Books, Baltimore. 
Pisa Cihan, R. Y Covarrubias L.

$196 \mathrm{t}$ El pueblo del jaguar, (Las olmeras anqueoligicos). Conscjo para la planeacion e instalación del Museo Nacional de Antropología, México.

Proskourlakofy, 'Thilana.

1960 "Historical Implications of a Pattern at Piedras Negras. Guatemala." American Antiquty. vol. 25. núm. 1: $454+75$. Salt Lake Gity.

1963 "Historical Data in the Inscriptions of Yaxchilan." Estudios de Cultura Maya. UNAM, vol. $\%, p$. 149.168, México.

1964 "Historical Data in the Inscriptions of Vaxchilan" (part II) . Estudios de Cullma Maya. I'N.A. vol. IV', pp. 177-202. México.

STIRLiNG, MATHEW W.

1965 "Monumental Sculpture of Southern Veracruz and Tabasco." Handbook of Middle Amercan Indians. Volume three. Part two, pp. 715. 738, Rolsert Wanchope General Editor. Iniversity of Texas Press, Austin.

Westheim, Pall.

1965 Arte antıguo de México. Fondo de Cultura Económica. 2a. ed., México. 